\title{
SUBMISSÃO DA TUTELA PENAL AO INTERESSE FISCAL NOS CRIMES DE SONEGAÇÃO TRIBUTÁRIA
}

\author{
SUBMISSION OF CRIMINAL PROTECTION TO TAX INTEREST IN \\ CRIMES OF TAX EVASION
}

\begin{abstract}
AdRIANO FARIAS PUERARI
Bacharel em Direito pela Universidade Federal de Santa Maria (UFSM). Integrante do NEAPRO/UFSM (www.ufsm.br/neapro). Membro do Escritório de Advocacia Bruno Menezes e Mário Cipriani Advocacia Criminal.
\end{abstract}

\begin{abstract}
RESUMO
Atualmente, a larga expansão das novas tecnologias lidera uma evolução cada vez maior do fenômeno da globalização, que tem como um de seus muitos desdobramentos 0 incremento da criminalidade econômica. O desenvolvimento político e econômico de um país é reflexo da abrangência do Direito Econômico que o tutela e, consequentemente, da ampliação do Direito Penal Econômico, pois o tratamento de questões que envolvam proteção aos crimes de colarinho branco é condição de possibilidade à proteção e à defesa de uma ordem jurídica justa. Nesse contexto, o presente artigo tem por objetivo analisar a evolução da delinquência econômica, identificando o bem jurídico protegido pelo Direito Penal Econômico de modo a confrontar a tutela penal frente aos interesses arrecadatórios da Administração, especialmente para demonstrar a impunidade que gira em torno dos delitos de sonegação fiscal.
\end{abstract}

Palavras-chave: Crimes do Colarinho Branco; Direito Penal Econômico; Sonegação Fiscal.

\begin{abstract}
Currently, the vast expansion of new technologies heads an increasing evolution of the globalization phenomenon, which has as one of its many splits the increment of economic criminality. The political and economic development of a country is a reflection of the Economic Law that tutelages it and, consequently, the expansion of the Economic Criminal Law, as the treatment of issues that involve protection to the white collar crimes which is the condition of possibility for the protection and defense of a fair economic order. In this context, this article aims to analyze developments in the economic criminality, identifying the legal interest protected by the Economic Criminal Law in order to confront the penal tutelage against the Administration interests in fund raising, especially to demonstrate the impunity that revolves around tax evasion crimes.
\end{abstract}

Keywords: White Collar Criminals; Economic Criminal Law; Tax Evasion.

\section{SUMÁRIO}

INTRODUÇAO; 1 A DELINQUÊNCIA ECONÔMICA EM EVIDÊNCIA; 1.1 A evolução dos crimes do colarinho branco; 1.20 bem jurídico tutelado pelo Direito Penal Econômico; 2 A (DES)VINCULAÇÃO DA TUTELA PENAL FRENTE AO INTERESSE FISCAL; 2.1 Da necessidade da tutela penal diante dos interesses arrecadatórios nos delitos tributários; 2.2 A impunidade nos crimes de sonegação fiscal; CONCLUSÃO; REFERÊNCIAS. 


\section{INTRODUÇÃO}

Hodiernamente, a ampla utilização das inovações tecnológicas permite uma expansão cada vez maior do fenômeno da globalização, que tem como um de seus muitos desdobramentos o incremento da criminalidade econômica.

Diante de uma sociedade que evoluiu no que tange aos seus aspectos tecnológicos, nasce essa nova forma de criminalidade que não existia para o Direito Penal Clássico. É uma criminalidade moderna, de uma sociedade de risco, na qual são proporcionadas situações que antes não eram contempladas, justamente em função da transformação dos sistemas econômicos.

Considerando que a abrangência do Direito Econômico e o consequente desenvolvimento do Direito Penal Econômico refletem a evolução política e econômica de um país, é de fundamental importância o estudo do Direito Penal Econômico e, mais especificamente, do Direito Penal Tributário ou Fiscal, já que o tributo (imposto) é o meio pelo qual se vale o Estado para controlar e organizar a economia.

Assim, tratar sobre questões que envolvam a proteção contra a delinquência econômica se torna cada vez mais necessário, uma vez que o ordenamento jurídico brasileiro prevê a defesa da ordem econômica com a devida observância dos princípios da livre concorrência e da redução das desigualdades sociais.

Destaca-se, nesse sentido, que muitos delitos cometidos em detrimento do Estado e que se enquadram numa classificação como crimes do colarinho branco, especialmente os de sonegação tributária, têm características próprias que demandam averiguação mais aprofundada, notadamente em função dos resultados que produzem.

Em relação aos efeitos dos delitos desse jaez, é possível assentar que possuem, regra geral, consequências mais lesivas que daquelas da delinquência tradicional. Isso porque se tratam de criminosos que realizam verdadeiro custo-benefício em relação aos resultados decorrentes de suas condutas e às possíveis implicações impostas em função do sistema punitivo legal.

Nesse contexto, o presente trabalho tem por objetivo inicial analisar a evolução da criminalidade econômica desde o seu desenvolvimento dogmático, que ocorreu a partir da 
década de 1920 para, após, identificar o bem jurídico tutelado pelo Direito Penal Econômico, de modo a apontar sua relevância para o sistema de controle penal contemporâneo.

A partir disso, o propósito final é confrontar a tutela penal frente aos interesses fiscaisarrecadatórios nos crimes de sonegação tributária, identificando e analisando as repercussões econômico-criminais dos institutos que tratam do assunto, com especial atenção à impunidade que dele se origina.

A análise do tema proposto conta com embasamento jurídico, doutrinário e jurisprudencial, tendo em vistas que foram analisadas as divergências a respeito da matéria. Com tal desiderato, utilizou-se o método dedutivo, pois o objeto da pesquisa foi trabalhado a partir da análise da evolução da criminalidade econômica e do bem jurídico subordinado a sua tutela, para então confrontá-la aos interesses arrecadatórios do Fisco.

$\mathrm{Na}$ elaboração da pesquisa foram adotados os métodos histórico e monográfico. 0 primeiro, utilizado objetivando a realização de um resgate histórico acerca da legislação e da jurisprudência que dizem respeito ao assunto. O método monográfico, por sua vez, foi empregado com o escopo de averiguar as consequências econômico-criminais, através de ponderações acerca da impunidade da delinquência econômica.

\section{A DELINQUÊNCIA ECONÔMICA EM EVIDÊNCIA}

Em pleno século XXI, os fatos põem-se em constante transformação, mormente se verificados a partir das relações sociais, altamente complexas. 0 avanço tecnológico houve por revolucionar as relações de tempo e espaço nas quais se desenvolvem as sociedades, provocando importantes transformações às noções de globalização econômica, sob cuja direção se guia a humanidade.

Estabeleceu-se, pois, uma nova realidade estatal econômica, possuidora de características próprias, tais como as novas relações entre o capital e o trabalho, a revolução dos meios de produção e transporte, o nascimento das empresas com investidores anônimos, as novas posições do mercado financeiro, a complexa interação dos fatores do mercado econômico, do trabalho e do mercado financeiro, dos preços, dos salários e das rendas.

A sociedade contemporânea, nesse contexto, clama por novos espectros de interesses e novas dimensões de direitos - sociais, coletivos e difusos - herdados do modelo de Estado Democrático de Direito. Paralelamente à criação de novas necessidades econômicas, alargam-se 
as já existentes, de natureza social, ainda pendentes de concretização. Daí por que se diz que o atual modo de produção do Direito exige um repensar. ${ }^{1}$

A ordem mundial mudou, e com ela se alterou também a questão criminal. A criminalidade de massa, que atenta individualmente contra bens jurídicos tradicionais, como patrimônio, a vida e a liberdade sexual, não mais representa a evidência dos debates. É a vez da criminalidade do poder, estabelecida através do "novo perigo" ou do "novo inimigo".

A esse respeito, leciona Luciano Feldens:

O crime, por exemplo, não mais representa, pura e singularmente, aquela hipótese atávica retratada em uma relação jurídica interindividual em que "A" (frequentemente Caio) se apropria, mediante fraude ou violência física, de um bem pertencente a "B" (usualmente Tício), situação por demais repetida nos manuais que, ante sua singeleza, resulta por oferecer à consciência jurídica acadêmica uma visão apenas parcial do objeto. Os conflitos de Direito Penal, na atualidade, fazem-se coletivos e sociais em sua sujeição passiva. ${ }^{2}$

A criminalidade atual é demonstrada pela avassaladora corrupção, pelos grandes escândalos financeiros, pela lavagem de dinheiro (frequentemente associada ao tráfico de drogas e ao financiamento de campanhas políticas) e, notadamente, pela estrondosa sonegação fiscal.

Esses delitos, devemos considerar, são praticados por uma determinada camada de pessoas, pertencentes a uma categoria profissional específica (empresários, diretores de empresa, de bancos, etc.) que, normalmente, escapam às rédeas do controle estatal.

Nesse ínterim, a forma complexa de cometimento desses crimes, sua gravidade e incidência socioeconômica, característica dessa delinquência, permite que se os relacione àquelas infrações penais que formam parte do que se convencionou denominar de Direito Penal Econômico ${ }^{3}$, a abarcar, essencialmente, os crimes contra a ordem econômico-tributária, em

\footnotetext{
1 A exigibilidade de repensar o Direito, ensina Lenio Luiz Streck, reflete-se na necessidade de compreender que o Direito, notadamente após o segundo pós-guerra, assumiu um caráter hermenêutico. Significa a impossibilidade de separação dos processos de produção, interpretação e aplicação do direito, demonstrando-se que é possível, a partir da noção de ser-no-mundo, viabilizada pela linguagem - vista como condição de possibilidade - ter acesso ao próprio mundo do direito, da vida e dos fatos. STRECK, Lenio Luiz. Hermenêutica Jurídica $\mathbf{e}(\mathrm{m})$ crise: uma exploração hermenêutica da construção do Direito. Porto Alegre: Livraria do Advogado, 2005. p. 179.

2 FELDENS, Luciano. Tutela penal de interesses difusos e crimes do colarinho branco. Porto Alegre: Livraria do Advogado, 2002. p. 23.

${ }^{3}$ Os acontecimentos políticos, econômicos e sociais do final do século XX determinaram a impossibilidade da formulação de um conceito estático para o Direito Penal Econômico. Já quanto a sua autonomia como ramo do direito, os acontecimentos avassaladores no campo das relações humanas e da diplomacia entre as nações apontam para uma separação definitiva entre o Direito Penal Clássico e o Direito Penal
} 
detrimento do sistema financeiro nacional e as infrações penais que se lhes façam correlatas, tal o exemplo dos crimes de lavagem de dinheiro. ${ }^{4}$

\subsection{A evolução dos crimes do colarinho branco}

Desde épocas mais distantes existem disposições que buscam combater infrações nas atividades relacionadas a economia, tais como a usura, a retenção de matérias-primas essenciais e as fraudes no pagamento de impostos. No entanto, o Direito Penal Econômico como conjunto de normas relativamente homogêneas e desvinculadas do Direito Penal nuclear, pode-se dizer, surgiu apenas no século $X X .^{5}$

Nesse sentido, nos países europeus, o desenvolvimento do moderno Direito Penal em matéria econômica remonta da década de 1920, seguindo-se às épocas de penúria dos períodos do pós-guerra, quando, efetivamente, surgiu o Direito Econômico e Industrial.

Ao lado dos mencionados conflitos bélicos, os conflitos financeiros, notadamente aqueles decorrentes da crise econômica gerada pelo crack da Bolsa de Valores de Nova York em 1929, foram igualmente relevantes para o Direito Penal Econômico, pois seus efeitos destruíram a cultura de tolerância excessiva de criminólogos, dogmáticos e práticos para com os abusos, a falta de escrúpulos ou mesmo a autofagia dos detentores do poder e do capital especulativo.

Arthur de Brito Gueiros Souza, no que concerne àquela época, explica que:

Assistiu-se, assim, a uma mudança de preocupações nas chamadas Ciências Criminais - ou seja, Direito Penal, Política Criminal e Criminologia -, agregandose, como o objeto de cada qual, não somente os delitos e os delinquentes clássicos da llustração, mas também novos atores e novas figuras delituosas, bem como necessidades de reformas legislativas e abordagens empíricas anteriormente ignoradas no cenário acadêmico. ${ }^{6}$

Econômico. COSTA, Elder Lisboa Ferreira da. Os delitos econômicos na atualidade. 0 crime de colarinho branco e a lavagem de dinheiro. In: D’AVILA, Fabio Roberto; SOUZA, Paulo Vinícius Sporleder de (Org.). Direito Penal Secundário: estudos sobre crimes econômicos, ambientais, informáticos e outras questões. São Paulo: Revista dos Tribunais, 2006. p. 342.

${ }^{4}$ FELDENS, Luciano. Tutela penal de interesses difusos e crimes do colarinho branco. Porto Alegre: Livraria do Advogado, 2002. p. 118.

${ }^{5}$ SOUZA, Arthur de Brito Gueiros. Da criminologia à política criminal: direito penal econômico e o novo direito penal. In: SOUZA, Arthur de Brito Gueiros (Org.). Inovações no Direito Penal Econômico: contribuições criminológicas, político-criminais e dogmáticas. Brasília: ESMPU, 2011. p. 105.

${ }^{6}$ Ibidem. p. 107. 
$\mathrm{Na}$ criminologia, particularmente, a reviravolta ocorreu com os trabalhos de Edwin $\mathrm{H}$. Sutherland, sociólogo norte-americano que em 1939, no $34^{\circ}$ Encontro da Sociedade Americana de Sociologia, apresentou exposição denominada The White Collar Criminal. ${ }^{7}$

Deixando de lado as tradicionais teorias da Criminologia, Sutherland propôs um conceito para o que denominou de crimes do colarinho branco, mas que deveria estar intimamente relacionado com a sua proposição denominada de associação diferencial, que consistia em uma teoria sociológica do comportamento criminal segundo a qual a conduta desviada era resultado de um procedimento de aprendizagem.

Sobre a teoria da associação diferencial, explica Sutherland (na tradução livre do autor):

A hipótese da associação diferencial é a de que o comportamento criminoso é aprendido a partir da associação daqueles que o definem como favorável em relação àqueles que o definem como não favorável e, esses, em uma situação apropriada, se envolvem em um comportamento criminoso se, e somente se, o peso das definições favoráveis exceder o peso das definições desfavoráveis. ${ }^{9}$

\footnotetext{
${ }^{7}$ Contudo, o Direito Penal Econômico foi adquirir verdadeiramente relevo científico somente a partir do VI Congresso da Associação Internacional de Direito Penal, ocorrido em Roma, em 1953. Nesse encontro é que foi atribuído a esse ramo do Direito a tutela das atividades econômicas regulamentadas não apenas pelo Estado, mas também por associações profissionais cujo escopo fosse o aumento e a justa distribuição de bens na sociedade. A partir desse período é que foi aceito o ilícito administrativo contravencional, culminando na separação entre as competências dos poderes Executivo e Judiciário. JAPIASSÚ, Carlos Eduardo Adriano; PEREIRA, Daniel Queiroz. Direito Penal Econômico e Tributário: uma análise histórica e comparada. In: SOUZA, Arthur de Brito Gueiros (Org.). Inovações no Direito Penal Econômico: contribuições criminológicas, político-criminais e dogmáticas. Brasília: ESMPU, 2011. p. 250.

${ }^{8}$ A expressão white collar crimes foi utilizada por Sutherland para se referir a uma pessoa de classe socioeconômica superior que viola as leis promulgadas para regular suas ocupações profissionais. 0 termo colarinho branco foi usado no mesmo sentido pelo Presidente da empresa General Motors ao escrever um livro denominado A autobiografia de um Trabalhador de Colarinho Branco. FISCHER, Douglas. Delinquência Econômica e Estado Social e Democrático de Direito. Porto Alegre: Verbo Jurídico, 2006. p. 112. Ainda, conforme Feldens, "O termo White collar crimes - expressão inglesa a designar os cognominados 'crimes do colarinho branco' - foi cunhado por Edwin H. Sutherland, a 27 de dezembro de 1939, quando de sua exposição perante a American Sociological Society. De trânsito comum em todos os idiomas, o termo batizou a clássica obra de Sutherland - White Collar Crime - em torno à delinquência do 'colarinho branco'. Conquanto construída, em meados do século XX, a partir de uma perspectiva sociológica, a tese veio a tornar-se referência no âmbito da criminologia, fixando-se como um marco científico e merecendo o aplauso e a respeitosa atenção da comunidade jurídica internacional". FELDENS, Luciano. Tutela penal de interesses difusos e crimes do colarinho branco. Porto Alegre: Livraria do Advogado, 2002. p. 115.

9 No original: "The hypothesis of differential association is the criminal behavior is learned in association with those who define such criminal behavior favorably and in isolation from those who define it unfavorably, and that person is an appropriate situation engages in such criminal behavior if, and only if, the weight of the favorable definitions exceeds the weight of the unfavorable definitions." SUTHERLAND, Edwin H. White Collar Crime. Lexington. KY, 2010. p. 240.
} 
Certificando haver uma aplicação diferenciada da lei em relação aos criminosos de colarinho branco, o americano constatou três circunstâncias das quais decorreriam tal problemática: a) o status do “homem de negócios", que the confere um grau de respeitabilidade no seio social, de modo que não é visto como um criminoso; b) a tendência a não castigar esse tipo de infração sob a ótica criminal; e c) a ausência de crítica e de compreensão dos efeitos dos delitos de colarinho branco pela sociedade.

Como bem sinaliza Fischer ${ }^{10}$, há ainda outro fator relevante que o sociólogo observou. Trata-se do sentimento de desprezo que os criminosos do colarinho branco expressam pela lei, pelo Estado e pelas pessoas responsáveis pela administração estatal. Na compreensão deles, quanto menor for a atuação interventiva do Estado, melhor será para a consecução de suas atividades.

A partir desse postulado, inaugurou-se uma revolução no objeto da criminologia, ampliando-se o foco da pesquisa para os indivíduos pertencentes aos extratos mais elevados da sociedade. Há, evidentemente, um rompante com a velha dicotomia, até então ignorada, de criminalidade versus pobreza.

Sutherland, portanto, deixou o legado - importantíssimo à Criminologia moderna - de que o Direito Penal não pune as ofensas aos bens jurídicos de forma e intensidade iguais. A carapuça de criminoso é atribuída aos indivíduos de forma diferenciada, sendo que a reação criminalizante e sua intensidade não variam de acordo com a gravidade das infrações. E que os delitos do colarinho branco, sob esta ótica, não são identificáveis, geralmente, como condutas criminosas aptas a ensejar enérgica intervenção estatal através da tutela penal.

Assim, como se pode intuir, é praticamente uma exigência metodológica, na atualidade, relacionar a teoria da associação diferencial à teorização dos crimes de colarinho branco e, por via de consequência, como se verá a seguir, à tutela do Direito Penal Econômico.

\subsection{0 bem jurídico tutelado pelo Direito Penal Econômico}

Como se pode extrair da teoria de Sutherland, as leis penais não implicam igual grau de ressentimento por parte da sociedade. Nesse diapasão, o grande mérito do americano foi o de ampliar a crítica à criminalidade para além do reducionismo exclusivamente biológico.

${ }^{10}$ FISCHER, Douglas. Delinquência Econômica e Estado Social e Democrático de Direito. Porto Alegre: Verbo Jurídico, 2006. p. 113. 
Sucede que essa concepção permitiu a concentração no delito e no delinquente de forma a identificar as condutas praticadas pelos criminosos da alta sociedade, trazendo à evidência atividades que permaneceram durantes anos na cifra oculta ${ }^{11}$ da criminalidade e que, além de não figurarem nas estatísticas oficiais, eram contempladas de forma absolutamente complacente.

É por isso que desde o advento da tese do sociólogo americano, a delinquência econômica vem se destacando cada vez mais aos olhos do Direito Penal, sendo que a forma complexa de cometimento desses delitos, suas particulares gravidade e incidência socioeconômica permitem vinculá-los ao denominado Direito Penal Econômico.

Acontece, porém, que o Direito Penal se depara, atualmente, com a imensa dificuldade de lidar com a evolução tecnológica ocorrida em escala exponencial, sensibilizada através da determinação de diversos setores da sociedade aos riscos causados por estas tecnologias.

Assim, o Direito como mecanismo científico de controle social inserido no compasso de evolução das ciências sociais não consegue regulamentar determinadas matérias sem subverter seus próprios padrões evolutivos. Em função disso, acaba funcionando com instância de legitimação de uma divisão da sociedade em castas.

Nessa linha de raciocínio é que reside a tutela dos bens jurídicos que se encontram sob a guarida de uma sociedade envolta aos braços da economia, considerando-se a ordem econômico-tributária como protagonista desse cenário, diante da sua relevância social.

Dentro desse contexto, o processo de globalização no qual se insere a sociedade contemporânea vivencia uma transformação dos governos, assim como das economias e o próprio cotidiano social. Esse processo promove uma aproximação de distintas realidades que são obrigadas a conviver, notadamente no âmbito econômico, já que o próprio interesse de expansão das economias se dá para além das fronteiras do Estado. Tal expansão intensifica as mazelas do modelo capitalista pela progressiva expropriação de grandes massas de pessoas, paralelamente ao aumento de concentração dos recursos produtivos.

Daí por que se evidencia, em contraposição, a necessidade imperiosa de intervenção do Estado na economia, conquanto a própria Constituição Federal a admite, ainda que sob uma

\footnotetext{
${ }^{11}$ A expressão cifra oculta da criminalidade - ou numerus obscurus ou delinquência oculta-, explica Lola Aniyar de Castro, trata-se do produto da diferença entre a criminalidade aparente - aquela que chega ao conhecimento das instituições oficiais, mas que não se fazem computar estatísticas - e a criminalidade real - aquela referente a quantidade de delitos verdadeiramente cometida em determinado momento histórico. Apud FELDENS, Luciano. Tutela penal de interesses difusos e crimes do colarinho branco. Porto Alegre: Livraria do Advogado, 2002. p. 132.
} 
ISSN 1981-3694

(DOI) $10.5902 / 198136947524$

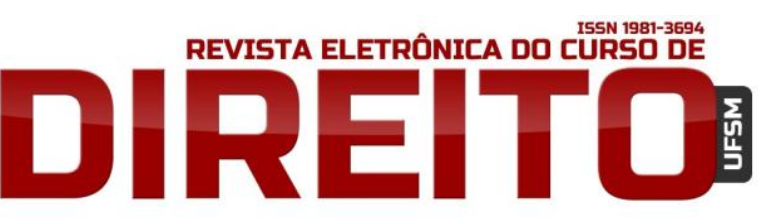

SUBMISSÃO DA TUTELA PENAL AO INTERESSE FISCAL NOS CRIMES DE SONEGAÇÃO TRIBUTÁRIA

ADRIANO FARIAS PUERARI

função regulatória ou de planejamento, fixada com a finalidade de controle dos abusos decorrentes do exercício da atividade econômica.

Independentemente da forma de participação do Estado no setor econômico, uma gama de valores sociais e coletivos estão a justificar o controle estatal das relações econômicas, precipuamente para o desenvolvimento salutar desse setor. Considera-se, nesse ponto, que a ordem econômica, de acordo com o artigo 170 da Constituição da República, faz-se fundada na valorização do trabalho humano e na livre iniciativa enquanto valores sociais aptos a ensejar a todos existência digna, conforme os ditames da justiça social. ${ }^{12}$

Exsurge da Constituição Econômica, pois, a ideia de bem jurídico coletivo, manifestada através do surgimento da tutela de interesses difusos, do que se permite observar o momento em que o Direito Penal, como anota Ela Wiecko Volkmer de Castilho, através da definição legal de crime econômico (Direito Penal Econômico) "satisfaz à necessidade de tutela da ordem econômica (Direito Econômico)". ${ }^{13}$

Possuindo como denominador comum a atividade econômica, o Direito Penal Econômico é tratado como a área do Direito Penal que se aglutina em um conjunto de normas penais que protegem a economia.

Nesse contexto, os crimes abarcados pelo Direito Penal Econômico, através da análise comparada entre os crimes de sonegação fiscal - tutela do patrimônio público - e os delitos comuns contra o patrimônio, tal qual o furto - aflitivo do patrimônio individual - permitem concluir pela carência de proteção a que se sujeitam os bens jurídicos coletivos.

É que os delitos econômicos podem ser considerados espécies de crimes contra o patrimônio, com elementares muito mais graves na medida em que não atingem interesses de alguns integrantes da sociedade, mas sim violam diretamente o funcionamento institucional do Estado.

A doutrina portuguesa reconhece em escala global a periculosidade dos crimes econômicos às sociedades contemporâneas:

A criminalidade económica, nas suas formas clássicas ou modernas, é um tema de marcada actualidade. Pela dimensão dos danos materiais e morais que provoca,

\footnotetext{
${ }^{12}$ Art. 170. A ordem econômica, fundada na valorização do trabalho humano e na livre iniciativa, tem por fim assegurar a todos existência digna, conforme os ditames da justiça social [...].BRASIL. Constituição Federal. Brasília: Senado Federal, 1988. Disponível em: <http://www.planalto.gov.br/ ccivil_03/constituicao/ConstituicaoCompilado.htm>. Acesso em: 15 ago. 2012.

13 CASTILHO, Ela Wiecko Volkmer de. O Controle Penal nos Crimes Contra o Sistema Financeiro Nacional. Belo Horizonte: Del Rey, 1998. p. 84.
} 
pela sua capacidade de adaptação e sobrevivência às mutações sociais e políticas, pela sua aptidão para criar defesas frustrando as formas de luta que the são dirigidas, a criminalidade econômica é uma ameaça séria a minar os alicerces de qualquer sociedade organizada. Daí que a invenção de formas eficazes de luta seja hoje preocupação das instâncias governativas, judiciais, policiais, etc., de todos os países. ${ }^{14}$

Já acerca do bem jurídico tutelado a partir dos delitos econômicos, explica Douglas Fischer:

Tradicionalmente, pensa-se em bens jurídicos que protejam objetos fisicamente individualizáveis e lesionáveis. Para a categoria dos delitos econômicos, normalmente não resta possível essa 'individualização', na medida em que os bens jurídicos são 'institucionais' ou difusos, referindo-se a um conjunto de condições sociais gerais, cujo atendimento é indispensável para uma convivência pacífica e próspera em sociedade. ${ }^{15}$

Baseando-se na classificação dos autores espanhóis Bajo Fernández e Bacigalupo, Luciano Feldens expõe que o delito econômico "é a infração jurídico-penal que coloca em risco a ordem econômica, assim entendida como regulação jurídica do intervencionismo estatal na economia de um país". ${ }^{16}$

Callegari, a respeito da finalidade e da função do Direito Penal Econômico, afirma que residem na:

sublimação da finalidade e a função do intervencionismo: cumprir as exigências de uma valoração diferente do imperativo de justiça na ordem das relações sociais e econômicas. Estas novas exigências se plasmam na necessidade de hoje assumida de proteger a economia e seu conjunto, a ordem econômica, a economia nacional colocada ao amparo do novo intervencionismo estatal, como interesses distintos aos particulares de propriedade patrimônio e fé contratual. ${ }^{17}$

O conteúdo (objeto), portanto, do Direito Penal Econômico abrange os delitos financeiros, a lavagem de dinheiro e os delitos fiscais ${ }^{18}$, de sorte que para o efeito de proteção penal, a noção de ordem econômica lato sensu, apreendida como ordem econômica do Estado

\footnotetext{
${ }^{14}$ DIAS, Jorge de Figueiredo e ANDRADE, Manuel da Costa. Problemática Geral das Infrações contra a Economia Nacional. In: Instituto de Direito Penal Econômico e Europeu (Coord.). Direito penal econômico e europeu: textos doutrinários. V. I. Coimbra: Coimbra, 1998. p. 319-320.

${ }^{15}$ FISCHER, Douglas. Delinquência Econômica e Estado Social e Democrático de Direito. Porto Alegre: Verbo Jurídico, 2006. p. 127.

${ }^{16}$ FELDENS, Luciano. Tutela penal de interesses difusos e crimes do colarinho branco. Porto Alegre: Livraria do Advogado, 2002. p. 123.

17 CALLEGARI, André Luis. Direito Penal Econômico e lavagem de dinheiro - aspectos criminológicos. Porto Alegre: Livraria do Advogado, 2003. p. 21.

${ }^{18}$ Ibidem.
} 
abrange, nos dizeres de Luiz Regis Prado "a intervenção estatal na economia, a organização, o desenvolvimento e a conservação dos bens econômicos (inclusive serviços), bem como sua produção, circulação, distribuição e consumo". ${ }^{19}$

Ainda, aprofunda o conceito o penalista:

Esse conceito de ordem econômica acaba por agasalhar as ordens tributária, financeira, monetária e a relação de consumo, entre outros setores, e constitui um bem jurídico-penal supra-individual, genericamente considerado (bem jurídico categorial), o que por si só não exclui a proteção de interesses individuais. Além disso, em cada tipo legal de injusto há um determinado bem jurídico específico ou em sentido estrito (essencialmente de natureza supraindividual), diretamente protegido em cada figura delitiva. Tal concepção fundamenta em sede penal um conceito amplo de delito econômico, mas não totalizador ou amplíssimo. ${ }^{20}$

Pode-se dizer, assim, que o Direito Penal Econômico se funda em torno da proteção da atividade econômica, de sorte que sua definição conceitual interage com o conjunto de normas jurídico-penais que protegem a ordem econômica. O delito econômico é, portanto, a infração jurídico-penal que lesiona ou coloca em risco a ordem econômica, assim entendida como regulação jurídica do intervencionismo estatal na economia de um país.

\section{A (DES)VINCULAÇÃO DA TUTELA PENAL FRENTE AO INTERESSE FISCAL}

Como premissa inicial, estabelece-se que deve permanecer indene de dúvidas o fato de que a delinquência do Direito Penal Econômico é exteriorizada como uma especialidade do Direito Penal, e não do Direito Econômico ou até mesmo do Direito Tributário. Por esse motivo, a matéria deve sofrer análise principiológica e teórica do Direito Penal, evitando-se concepções tendentes a neutralizá-lo na reação econômico-tributária. ${ }^{21}$

A partir dessa perspectiva criminal é que se pode considerar que o conteúdo do Direito Penal Econômico abrange os delitos financeiros, a lavagem de dinheiro e os delitos fiscais. ${ }^{22}$ Seguindo, pois, essa perspectiva, é que centramos o objeto deste trabalho aos crimes contra a

\footnotetext{
${ }^{19}$ PRADO, Luiz Regis. Direito Penal Econômico. 2. ed. São Paulo: Revista dos Tribunais, 2007. p. 37.

${ }^{20}$ Ibidem, p. 38.

${ }^{21}$ FELDENS, Luciano. Tutela penal de interesses difusos e crimes do colarinho branco. Porto Alegre: Livraria do Advogado, 2002. p. 124.

${ }^{22}$ BAJO FERNÁNDEZ, Miguel; BACIGALUPO, Silvina. Derecho Penal Económico. Madrid: Centro de Estudios Ramón Areces, S.A., 2001. p. 14.
} 
ordem econômico-tributária, previstos na Lei $8.137 / 90$, principalmente os do artigo $1^{\circ}$, de sonegação fiscal. ${ }^{23}$

É que ao se encarar o tributo, especialmente o imposto, como um instrumento de que se vale o Estado para controlar e organizar a economia, torna-se possível considerá-lo um instituto jurídico apto a ensejar a tutela do Direito Penal Econômico. Nesse sentido, Japiassú e Pereira definem:

O Direito Penal Tributário ou Fiscal deve também ser entendido com um direito sancionador das violações da ordem econômica. Tal assertiva se encontra fundada no fato de que o tributo, notadamente o imposto, consiste em um instrumento jurídico a ser utilizado pelo Estado na regulação, intervenção ou mesmo direção do sistema econômico. ${ }^{24}$

A tutela nos delitos desse jaez se dá em função da proteção à ordem tributária, justificada por seu caráter supraindividual ${ }^{25}$ e não limitada apenas em razão da arrecadação de receitas, mas também na realização de objetivos de justiça distributiva, levando em consideração as necessidades de financiamento das atividades sociais do Estado. ${ }^{26}$

\footnotetext{
${ }^{23}$ Art. $1^{\circ}$. Constitui crime contra a ordem tributária suprimir ou reduzir tributo, ou contribuição social e qualquer acessório, mediante as seguintes condutas: I) omitir informação, ou prestar declaração falsa às autoridades fazendárias; II) fraudar a fiscalização tributária, inserindo elementos inexatos, ou omitindo operação de qualquer natureza, em documento ou livro exigido pela lei fiscal; III) falsificar ou alterar nota fiscal, fatura, duplicata, nota de venda, ou qualquer outro documento relativo à operação tributável; IV) elaborar, distribuir, fornecer, emitir ou utilizar documento que sabia ou deva saber falso ou inexato; V) negar ou deixar de fornecer, quando obrigatório, nota fiscal ou documento equivalente, relativa a venda de mercadoria ou prestação de serviço, efetivamente realizada, ou fornecê-la em desacordo com a legislação [...] BRASIL. Lei $n^{\circ}$ 8.137, de 27 de dezembro de 1990. Define os crimes contra a ordem tributária, econômica e contra as relações de consumo, e dá outras providências. In: Diário Oficial da República Federativa do Brasil, Brasília, DF, 28 dez. 1990. Disponível em: <http://www.planalto.gov.br/ ccivil_03/leis/L8137.htm>. Acesso em: 27 ago. 2012.

24 JAPIASSÚ, Carlos Eduardo Adriano. PEREIRA, Daniel Queiroz. Direito Penal Econômico e Tributário: uma análise histórica e comparada. In: SOUZA, Arthur de Brito Gueiros (org.). Inovações no Direito Penal Econômico: contribuições criminológicas, político-criminais e dogmáticas. Brasília: ESMPU, 2011. p. 253.

${ }^{25}$ Esse caráter supraindividual a que se faz referência decorre do fato de que os recursos auferidos das receitas tributárias é que resguardam a economia estatal para a realização das atividades destinadas a atender as necessidades sociais e os encargos públicos do orçamento. Em não sendo esses recursos suficientes, será a atividade tributária do Estado a responsável pelo ingresso de recursos para atender aos gastos. PRADO, Luis Regis. Direito Penal Econômico. 3. ed. São Paulo: Revista dos Tribunais, 2009. p. 399.

${ }^{26}$ RODRIGUES, Anabela Miranda. Contributo para a fundamentação de um discurso punitivo em matéria fiscal. In: Instituto de Direito Penal Económico e Europeu. (Coord.). Direito penal econômico e europeu: textos doutrinários. V. II Coimbra: Coimbra, 1999. p. 481
} 
A partir da necessidade de proteção desses institutos é que se realiza o confronto da tutela penal frente aos interesses fiscais-arrecadatórios, partindo-se do pressuposto de desvinculação entre os temas.

\subsection{Da necessidade da tutela penal diante dos interesses arrecadatórios nos delitos tributários}

Ao Estado cumpre garantir, conjuntamente com uma série de prestações sociais, a igualdade entre os cidadãos. Deve, pois, criar um ambiente de segurança jurídica e econômica que estabeleça o desenvolvimento.

Contudo, para o cumprimento do extenso rol de atribuições que thes são conferidas, torna-se imprescindível a obtenção de recursos. E é a atividade tributária a fonte principal pela qual o Estado obtém esses recursos.

A tributação assegura ao Estado as receitas financeiras, contínua e regularmente, para o atendimento dos seus fins, que podem ser resumidos na satisfação de interesses coletivos, isto é, na realização do bem comum. Para isso, retira dos particulares, coativamente, parcela da riqueza por eles produzida.

Como nem todos têm igual nível de riqueza, através do preceito de progressividade, a tributação é graduada de acordo com a capacidade contributiva de cada um, com o intuito de fazer cumprir os ideários de uma sociedade livre, justa e solidária, estabelecidos no artigo $3^{\circ}$ da Constituição Federal.

Disso deriva o princípio da generalidade da tributação, em razão do qual todos devem pagar tributos, e o princípio da universalidade da tributação, segundo o qual, todos os bens, serviços e patrimônios devem ser atingidos pelos tributos.

Por tudo isso, é que se reconhece no dever fundamental de pagar tributos a legitimidade constitucional dos crimes tributários.

Para José Maria de Castro Panoeiro ${ }^{27}$, tributos não são um custo ou um ônus, são o preço a que se deve pagar a fim de que o Estado possa garantir um modelo de sociedade em que todos tenham liberdades, econômicas ou não, e possam atingir a plenitude de suas capacidades, quaisquer que sejam.

27 PANOEIRO, José Maria de Castro. As controvérsias da Lein. 8.137/1990 (sonegação fiscal) e suas repercussões econômico-criminais. In: SOUZA, Arthur de Brito Gueiros (Org). Inovações no Direito Penal Econômico: contribuições criminológicas, político-criminais e dogmáticas. Brasília: ESMPU, 2011. p. 305. 
Na doutrina lusitana, Anabela Miranda Rodrigues alerta para o fundamento constitucional da cobrança de impostos, como dever do cidadão:

É sabido que ao Estado hoje cabe assegurar ao cidadão não só a liberdade de ser como a liberdade para o ser. E a satisfação de prestações necessárias à existência do indivíduo em sociedade deve ser garantida pelo Estado ao mesmo nível que a protecção dos seus direitos fundamentais, quando estiver em causa a lesão ou perigo de lesão dos interesses ou valores aí contidos - o que vale por dizer, ao nível penal. Bens jurídicos dignos desta proteção são, na verdade, tanto aqueles que surgem como concretização de valores jurícico-constitucionais ligados aos direitos sociais e à organização econômica, como os que surgem como concretização de valores ligados aos direitos, liberdades e garantias.

Este fundamento ético do imposto, legitimado a expansão do direito penal a um domínio tradicionalmente alheio a esta dignificação, está contido claramente na Constituição (arts. $103 .^{\circ}$ e $104 .^{\circ}$ ), que aponta ao sistema fiscal uma finalidade de repartição justa dos rendimentos e da riqueza, a diminuição das desigualdades, a igualdade dos cidadãos e a justiça social. ${ }^{28}$

A respeito dos deveres constitucionais (de pagamento de tributos), Douglas Fischer assevera que

Se inexiste explicitamente previsão em nossa Constituição Federal de título ou capítulo tratando dos deveres fundamentais - senão apenas dos direitos -, é preciso considerar que eles se constituem em exigência estrutural de qualquer Constituição, sendo, na verdade, expressão da soberania fundada na dignidade da pessoa humana, traduzindo-se em verdadeiros custos para a concretização de todos os pressupostos nos quais aquela se funda.

As normas relativas aos deveres (mesmo que implícitas) em determinadas relações sociais ou em certos âmbitos da autonomia pessoal dos cidadãos decorrem da fórmula de um Estado Social. ${ }^{29}$

Reconhecida, pois, a existência de um bem jurídico relacionado ao dever geral de pagar impostos, devemos admitir como um equívoco a lógica meramente patrimonialista que gira em torno dos crimes tributários e repercute na construção de uma legislação e de uma jurisprudência fundadas na submissão da tutela penal aos interesses arrecadatório-fiscais.

Com efeito, atenta-se ao artigo 83 da Lei 9.430/1996, que impede que os agentes do Fisco façam a representação fiscal para fins penais antes de encerrada a instância administrativa. ${ }^{30}$

${ }^{28}$ RODRIGUES, Anabela Miranda. Contributo para a fundamentação de um discurso punitivo em matéria penal fiscal. In: Instituto de Direito Penal Econômico e Europeu (Coord.). Direito penal econômico e europeu: textos doutrinários. V. II. Coimbra: Coimbra, 1998. p. 481.

${ }^{29}$ FISCHER, Douglas. Delinquência Econômica e Estado Social e Democrático de Direito. Porto Alegre: Verbo Jurídico, 2006. p. 129. 
Trata-se da necessidade de decisão administrativa tributária final como condição para a incidência da norma que relata os crimes contra a ordem tributária.

Ocorre que, como bem adverte Panoeiro ${ }^{31}$, o interesse fiscal é de mera arrecadação de tributos, motivado por questões de eficiência, sendo que o interesse penal não diz respeito a esse caráter patrimonial. A tutela penal é muito mais do que isso, pois mantém preocupação com a violação de uma norma de conduta, independentemente do montante do prejuízo patrimonial.

O que se percebe é que desde a edição da mencionada lei, vem se encampando algum tipo de controle político em torno dos crimes tributários. Se, antes da lei, o agente fiscal ao tomar conhecimento por meio de fiscalização da ocorrência de crimes, podia fazer a comunicação direta ao Ministério Público, a partir de então, o referido artigo 83 passou a restringir esse tipo de procedimento.

Sucede, entretanto, que a tutela penal não pode, sob hipótese nenhuma, submeter-se a qualquer condicionamento administrativo que vise ao recolhimento de tributos, uma vez que as penalidades aplicadas aos delitos fiscais não têm por objeto imediato a tutela dos interesses das pessoas jurídicas prejudicadas pelo ato ilícito - no caso, os entes federativos credores -, mas, conforme se vê da lição da doutrina portuguesa, há um interesse geral de prevenção da sociedade:

\begin{abstract}
Qual será, pois, o interesse que constitui o objecto imediato da tutela consubstanciada nas penas fiscais? Necessariamente, um interesse geral da sociedade, personalizada no Estado: afastada a hipótese de se tratar de um interesse do credor do imposto - única pessoa jurídica directamente lesada com o acto ilícito -, tem de admitir-se que é um interesse geral a impor a cominação de penas fiscais. Ora, esse interesse geral (interesse do Estado, enquanto expressão jurídica da sociedade), ligado à cominação de sanções para os autores de determinados actos ilícitos, não pode deixar de ser o interesse em que esses actos deixem de ser praticados, quer pelas mesmas pessoas (prevenção especial), quer por outras (prevenção geral).
\end{abstract}

\footnotetext{
${ }^{30}$ Art. 83. A representação fiscal para fins penais relativa aos crimes contra a ordem tributária previstos nos arts. $1^{\circ}$ e $2^{\circ}$ da Lei n. 8.137, de 27 de dezembro de 1990, [...] será encaminhada ao Ministério Público depois de proferida a decisão final, na esfera administrativa, sobre a exigência fiscal do crédito tributário correspondente". BRASIL. Lei $n^{\circ}$ 9.430, de 27 de dezembro de 1996. Dispõe sobre a legislação tributária federal, as contribuições para a seguridade social, o processo administrativo de consulta e dá outras providencias. In: Diário Oficial da República Federativa do Brasil. Brasília, DF, 28 dez. 1996. Disponível em: <http://www.planalto.gov.br/ccivil_03/leis/l9430.htm>. Acesso em: 17 ago. 2012.

31 PANOEIRO, José Maria de Castro. As controvérsias da Lei n. 8.137/1990 (sonegação fiscal) e suas repercussões econômico-criminais. In: SOUZA, Arthur de Brito Gueiros (Org). Inovações no Direito Penal Econômico: contribuições criminológicas, político-criminais e dogmáticas. Brasília: ESMPU, 2011. p. 307.
} 
Chegamos assim à importantíssima conclusão de os fins últimos das penas criminais (fins preventivos) caracterizam também as penas fiscais. ${ }^{32}$

Até porque, como refere Mário Cipriani, as condutas dos delitos econômicos representam uma:

periculosidade silenciosa, maligna, amorfa e sub-reptícia alarmante que merece por parte do Judiciário uma enérgica e corajosa tomada de atitude para coibir, quando chamada a atuar dentro do devido processo legal, a prática desses delitos causadores da falência da Nação. ${ }^{33}$

O fato é que é sobre a própria organização social que os crimes do colarinho branco demonstram seus efeitos mais nefastos, já que influenciam diretamente no aumento da desigualdade de classes econômicas, haja vista que retiram da sociedade os já escassos recursos financeiros, aumentando a pobreza e a miséria.

Malgrado toda a demonstração da periculosidade dos crimes sujeitos ao Direito Penal Econômico, há autores que questionam a legitimidade democrática dos white collar criminals.

Nessa linha, destaca-se Gonzalo Rodríguez Mourullo, quando sustenta (na tradução livre do autor) que:

A criminalização da infração fiscal pode responder a duas abordagens diferentes: pode ser fruto da convicção de que se alcançou um sistema fiscal, em que se sabe que ganhou o respeito de todos e que, portanto, a violação das normas tributárias seria intolerável, ou pode ser o produto da comparação estatística de que quase todo mundo frauda e que, por conseguinte, é preciso desencadear o terror penal para que as pessoas paguem os tributos. A primeira abordagem parece bem sucedida. A segunda questão inadmissível, porque pretende usar a pena criminal com fins meramente utilitaristas para encobrir um fracasso definitivo do próprio sistema fiscal. ${ }^{34}$

\footnotetext{
${ }^{32}$ ROSA, Manuel Cortes. Natureza jurídica das penas fiscais. In: Instituto de Direito Penal Econômico e Europeu (Coord.). Direito penal econômico e europeu: textos doutrinários. V. II. Coimbra: Coimbra, 1998. p. 11.

${ }^{33}$ CIPRIANI, Mário Luís Lírio. A aplicação da pena privativa de liberdade aos White-collar criminals. Revista Jurídica. Sapucaia do Sul, RS, v. 49, n. 289, 2001. p. 58.

34 "La criminalización de la infracción tributaria puede responder a dos planteamientos diferentes: puede ser el fruto de la convicción de que se ha logrado un sistema fiscal, dentro de lo que sabe, justo, merecedor del respeto de todos y de que, por tanto La infracción tributaria resulta intolerable, o puede ser el producto de la comprobación estadística de que casi todo el mundo defrauda y que, por consiguinte, es preciso desencadenar el terror penal para que la gente satisfaga los tributos. El primer planteamiento parece acertado. El segundo inadmisible, porque pretende usar la pena criminal, con fines meramente utilitaristas, para encubrir en definitiva un fracaso del propio sistema fiscal." Apud MACHADO, Hugo de Brito. Crimes contra a ordem tributária. São Paulo: Atlas, 2008. p. 202.
} 
Provido de maior sensatez, mas seguindo igual linha de descriminalização, Cipriani propõe

E a idéia é precisamente esta: um direito penal fundado no princípio da intervenção mínima não pode ficar conhecido como um direito penal orientado à eficácia, que elimina as barreiras tradicionais do direito penal garantista. A medida mais usada, quando há crescimento da criminalidade, é o aumentar de penas (pseudo), solução muito recorrida em tempos atuais, nomeadamente pela mídia e pelos políticos. Mas há outras formas de controle social ou outros meios de política criminal aptos a aplacar o problema. [...] poder-se-iam adotar regras que pudessem ser aplicadas em qualquer país, nos casos de crimes de corrupção, tráfico de drogas e lavagem de dinheiro etc., assim como em tratados internacionais deveriam ser instituídos instrumentos eficazes, tornando compatível a legislação própria com a legislação alienígena, visando o maior interesse dos povos, a dignidade, a cidadania e o bem comum. E, no âmbito preventivo-administrativo, novas opções poderiam ser criadas, como a reestruturação empresarial, a inserção de agentes fiscalizadores dentro das empresas, uso mais alargado de auditorias, políticas de sanidade empresarial, com a demissão imediata de funcionários desonestos, prática de termos de ajustamentos com o Ministério Público e também por ele, ajuizamento de ações civis públicas ou de reparação de danos, comissões de trabalhadores, de consumidores etc. ${ }^{35}$

0 argumento, em linhas gerais, da doutrina que defende a limitação ou a não-intervenção penal no domínio econômico é de que os tributos seriam criados por normas de rejeição social, sem qualquer carga de conteúdo moral que lhes prestasse suporte, de modo que o seu descumprimento se assemelharia a uma desobediência civil ou a uma objeção da consciência. ${ }^{36}$

Ora, é de fácil constatação a impotência do Direito Civil e, ainda que sancionatória, a do Direito Administrativo. As sanções administrativas geralmente não possuem poder preventivo e dissuasório, próprio das penas criminais, e, quando pecuniárias, acabam por integrar os ajustes contábeis das empresas, tornando-se riscos calculáveis. ${ }^{37}$

Poderiam, pois, nessa linha, ser superadas sem grandes dificuldades pela própria pujança financeira do infrator ou até mesmo integralizadas aos próprios preços praticados na comercialização dos serviços e produtos dos criminosos econômicos, em uma avaliação de custo-

${ }^{35}$ CIPRIANI, Mário Luís Lírio. Direito penal econômico e legitimação da intervenção estatal. In: D’AVILA, Fabio Roberto; SOUZA, Paulo Vinícius Sporleder de (Org.). Direito Penal Secundário: estudos sobre crimes econômicos, ambientais, informáticos e outras questões. São Paulo: Revista dos Tribunais, 2006. p. 461. ${ }^{36}$ RODRIGUES, Savio Guimarães. O bem jurídico-penal tributário e a legitimidade constitucional do sistema punitivo em matéria fiscal. In: SOUZA, Arthur de Brito Gueiros (Org). Inovações no Direito Penal Econômico: contribuições criminológicas, político-criminais e dogmáticas. Brasília: ESMPU, 2011. p. 356.

37 Jorge de Figueiredo Dias apud RODRIGUES, Savio Guimarães. O bem jurídico-penal tributário e a legitimidade constitucional do sistema punitivo em matéria fiscal. In: In: SOUZA, Arthur de Brito Gueiros (Org). Inovações no Direito Penal Econômico: contribuições criminológicas, político-criminais e dogmáticas. Brasília: ESMPU, 2011. p. 361. 
benefício capaz, inclusive, de incentivar a prática dos delitos que se quer combater. Seria, em última análise, a transposição da penalidade ao próprio consumidor. ${ }^{38}$

Os delinquentes econômicos realizam uma ação delitiva com certa dose de racionalidade, na medida em que fazem verdadeiro cálculo dos custos e vantagens que cada ação proporciona. Esses sujeitos, portanto, somente cometerão um fato delitivo se a sanção esperada for inferior às vantagens privadas esperadas com a realização do ato.

Semelhante linha de raciocínio apresenta Schünemann, ao sustentar "que o mecanismo específico de eficácia do direito Penal - diferentemente do Direito Administrativo ou Civil consiste em estabelecer custos muito superiores aos benefícios do delito". ${ }^{39}$

Por isso, proteger o Estado destes malfeitores pode ser considerado uma política de justiça social. Nesse sentido, qualquer rejeição à ideia dos crimes do colarinho branco como delitos, relegando-os ao âmbito sancionador meramente administrativo, os tornaria insuscetíveis de punições proporcionais à lesividade das condutas praticadas e à importância dos bens jurídicos atingidos.

É, portanto, imperioso que o Estado intervenha de forma enérgica nesses casos, procurando efetivar, por meio do jus puniendi, os princípios corolários do Estado Democrático de Direito.

Não é, todavia, o que se tem verificado na atividade legiferante, nem tampouco o que se praticado nos tribunais pátrios.

Com efeito, tudo gira em torno do malsinado artigo 83 da Lei $n^{\circ} 9.430 / 1996$, que desde a sua edição vem tramando uma espécie de controle político em torno dos crimes de sonegação fiscal.

Se, antes desse dispositivo, o agente do fisco podia fazer comunicação imediata ao Ministério Público ao tomar ciência por meio de fiscalização da ocorrência de crimes, a partir dele, o procedimento se restringiu.

Não foi por outra razão que acabou sendo questionado por meio da Ação Direta de Constitucionalidade $n^{\circ} 1.571 / D F$, que se fundava nos artigos $1^{\circ}, 2^{\circ}, 3^{\circ}, 5^{\circ}$, caput e inciso XXXV,

\footnotetext{
${ }^{38}$ RODRIGUES, Savio Guimarães. O bem jurídico-penal tributário e a legitimidade constitucional do sistema punitivo em matéria fiscal. In: In: SOUZA, Arthur de Brito Gueiros (Org). Inovações no Direito Penal Econômico: contribuiç̧̃es criminológicas, político-criminais e dogmáticas. Brasília: ESMPU, 2011. p. 361.

${ }^{39}$ Apud FISCHER, Douglas. O custo social da criminalidade econômica. In: SOUZA, Arthur de Brito Gueiros (Org). Inovações no Direito Penal Econômico: contribuições criminológicas, político-criminais e dogmáticas. Brasília: ESMPU, 2011. p. 37.
} 
artigo 37 , caput, artigo $60, \S 4^{\circ}$, inciso III, artigo 129, inciso I e artigo 170, todos da Constituição Federal.

A alegação era de que se estaria criando uma condição de procedibilidade e violando o disposto no artigo 129, inciso I, da Constituição Federal ${ }^{40}$, ao limitar o exercício da função institucional do Ministério Público para promover a ação penal, bem como restringindo os poderes para a propositura da ação penal.

O Supremo Tribunal Federal, porém, afastou este entendimento e decidiu que a norma se dirigia apenas ao agente fiscal, não ao Órgão Ministerial, motivo pelo qual não haveria nenhum vício de inconstitucionalidade. É o que se verifica da ementa, in verbis:

Ação direta de inconstitucionalidade. 2. Lei no 9430, de 27.12.1996, art. 83. 3. Argüição de inconstitucionalidade da norma impugnada por ofensa ao art. 129, I, da Constituição, ao condicionar a notitia criminis contra a ordem tributária "a decisão final, na esfera administrativa, sobre a exigência fiscal do crédito tributário", do que resultaria limitar o exercício da função institucional do Ministério Público para promover a ação penal pública pela prática de crimes contra a ordem tributária. 4. Lei $n^{\circ} 8137 / 1990$, arts. $1^{\circ}$ e $2^{\circ}$. 5. Dispondo o art. 83, da Lei $n^{\circ} 9430 / 1996$, sobre a representação fiscal, há de ser compreendido nos limites da competência do Poder Executivo, o que significa dizer, no caso, rege atos da administração fazendária, prevendo o momento em que as autoridades competentes dessa área da Administração Federal deverão encaminhar ao Ministério Público Federal os expedientes contendo notitia criminis, acerca de delitos contra a ordem tributária, previstos nos arts. $1^{\circ}$ e $2^{\circ}$, da Lei $n^{\circ} 8137 / 1990$. 6. Não cabe entender que a norma do art. 83, da Lei $n^{\circ}$ 9430/1996, coarcte a ação do Ministério Público Federal, tal como prevista no art. 129, I, da Constituição, no que concerne à propositura da ação penal, pois, tomando o MPF, pelos mais diversificados meios de sua ação, conhecimento de atos criminosos na ordem tributária, não fica impedido de agir, desde logo, utilizando-se, para isso, dos meios de prova a que tiver acesso. 7. 0 art. 83, da Lei $n^{\circ} 9430 / 1996$, não define condição de procedibilidade para a instauração da ação penal pública, pelo Ministério Público. 8. Relevância dos fundamentos do pedido não caracterizada, o que é bastante ao indeferimento da cautelar. 9. Medida cautelar indeferida. ${ }^{41} 42$

\footnotetext{
${ }^{40}$ Art. 129. São funções institucionais do Ministério Público: I - promover, privativamente, a ação penal pública, na forma da lei. BRASIL. Constituição Federal. Brasília: Senado Federal, 1988. Disponível em: <http://www.planalto.gov.br/ccivil_03/constituicao/ConstituicaoCompilado.htm>. Acesso em 22 nov. 2012.

41 BRASIL. Supremo Tribunal Federal. Ementa. ADI 1571/UF. Ação Direta de Inconstitucionalidade. Procurador-Geral da República e Presidente da República, Congresso Nacional. Relator: Ministro Gilmar Mendes. 10 dez. 2003. Disponível em: <http://www.stf.jus.br/portal/jurisprudencia/listar Jurisprudencia.asp?s1=\%28ADI\%24.SCLA.+E+1571.NUME.\%29+OU+\%28ADI.ACMS.+ADJ2+1571.ACMS.\%29\&base =baseAcordaos>. Acesso em: 20 ago. 2012.

${ }^{42}$ A ADI no 1571-1, de relatoria do Ministro Gilmar Mendes (em razão da aposentadoria do Ministro Néri da Silveira), por maioria, foi julgada improcedente e firmou a constitucionalidade do artigo 83, caput, da Lei Federal $n^{\circ}$ 9.430, de 27 de dezembro de 1996, vencidos o Ministro Carlos Britto e a Ministra Ellen Gracie,
} 
Ainda que a ementa tenho feito valer a norma do artigo 15 da Lei $n^{\circ} 8.137 / 1990^{43}$, a decisão deixara transparecer que em breve estaria a persecução penal condicionada a um pronunciamento administrativo.

Nessa órbita - e coincidentemente no mesmo dia - veio à evidência o Habeas Corpus $\mathrm{n}^{\circ}$ 81.611/SP, que alterou absolutamente o panorama, modificando o entendimento até então consolidado de que os crimes materiais independiam do esgotamento da questão na via administrativa.

No julgamento, de relatoria do Ministro Sepúlveda Pertence, o Plenário do STF passou a entender que a tipificação dos crimes materiais contra a ordem tributária deveria aguardar o lançamento do tributo na esfera administrativa. Nesse sentido, a ementa:

I. Crime material contra a ordem tributária (L. 8137/90, art. $1^{\circ}$ ): lançamento do tributo pendente de decisão definitiva do processo administrativo: falta de justa causa para a ação penal, suspenso, porém, o curso da prescrição enquanto obstada a sua propositura pela falta do lançamento definitivo. 1. Embora não condicionada a denúncia à representação da autoridade fiscal (ADInMC 1571), falta justa causa para a ação penal pela prática do crime tipificado no art. $1^{\circ} \mathrm{da}$ L. 8137/90 - que é material ou de resultado -, enquanto não haja decisão definitiva do processo administrativo de lançamento, quer se considere o lançamento definitivo uma condição objetiva de punibilidade ou um elemento normativo de tipo. 2. Por outro lado, admitida por lei a extinção da punibilidade do crime pela satisfação do tributo devido, antes do recebimento da denúncia (L. 9249/95, art. 34), princípios e garantias constitucionais eminentes não permitem que, pela antecipada propositura da ação penal, se subtraia do cidadão os meios que a lei mesma the propicia para questionar, perante o Fisco, a exatidão do lançamento provisório, ao qual se devesse submeter para fugir ao estigma e às agruras de toda sorte do processo criminal. 3. No entanto, enquanto dure, por iniciativa do contribuinte, o processo administrativo suspende o curso da prescrição da ação penal por crime contra a ordem tributária que dependa do lançamento definitivo. 4445

que julgavam procedente e declaravam a inconstitucionalidade do respectivo dispositivo. Decisão plenária, proferida em 10/12/2003, publicada no Diário da Justiça da União em 30/04/2004. p. 27.

${ }^{43}$ Art. 15 . Os crimes previstos nesta lei são de ação penal pública, aplicando-se-lhes o disposto no art. 100 do Decreto-Lei $n^{\circ} 2.848$, de 7 de dezembro de 1940 - Código Penal. BRASIL. Lei $n^{\circ}$ 8.137, de 27 de dezembro de 1990. In: Diário Oficial da República Federativa do Brasil, Brasília, DF, 28 dez. 1990. Disponível em: <http://www.planalto.gov.br/ccivil_03/leis/L8137.htm>. Acesso em: 27 ago. 2012.

${ }^{44}$ BRASIL. Supremo Tribunal Federal. Ementa. HC 81.611/DF. Ministério Público Federal e Luiz Alberto Chemim. Relator: Ministro Sepúlveda Pertence. 10 dez. 2003. Disponível em: < http://redir.stf.jus.br/paginadorpub/paginador.jsp?docTP=AC\&docID=78807>. Acesso em: 26 nov. 2012.

${ }^{45} \mathrm{Em}$ razão de ter omitido do fisco receitas decorrentes da prestação de serviços, o paciente foi processado por violação do artigo $1^{\circ}$, incisos I e II, da Lei $\mathrm{n}^{\circ} 8.137 / 90 \mathrm{c} / \mathrm{c}$ o artigo 71 , do Código Penal (sonegação de R\$ 490.449,13). Impetrou então habeas corpus perante o Tribunal Regional Federal da $3^{\text {a }}$ Região o qual restou indeferido. Desse resultado, ajuizou recurso ordinário ao Superior Tribunal de Justiça 
Referido julgamento serviu, ainda, de leading case para edição da Súmula Vinculante $\mathrm{n}^{\circ}$ 24 do Supremo Tribunal Federal, que estabelece que: "Não se tipifica crime material contra a ordem tributária, previsto no art. $1^{\circ}$, incisos I a Iv, da Lei $n^{\circ} 8.137 / 90$, antes do lançamento definitivo do tributo".

\subsection{A impunidade nos crimes de sonegação fiscal}

Conforme demonstrado, há certa tendência legal e jurisprudencial - considerado, especialmente, o entendimento do Supremo Tribunal Federal - em não considerar tipificados os crimes de sonegação fiscal antes do exaurimento definitivo na esfera administrativa do lançamento do tributo.

O problema é que a maior consequência dessa premissa é a impunidade que se desenvolve em torno do cometimento de crimes dessa espécie. Com efeito, a aprovação de súmula vinculante com tal conteúdo e com as implicações que dele decorrem deveria vir obrigatoriamente acompanhada de reflexão acerca das dimensões da sonegação fiscal no país.

Se houvessem métodos e estruturas eficientes para o combate à sonegação de impostos, seguramente poderia se cogitar o estabelecimento de programas de eliminação da pobreza extrema, de melhoria das condições de saúde, de educação, enfim, de tudo aquilo que se almeja para o país.

Entretanto, os institutos acima analisados permitem verificar que nesses casos é retirado do Estado o jus puniendi apto a ensejar persecução criminal em razão da conduta cometida, incidindo-se requisitos não previstos em lei para o exercício da ação penal.

Por isso, o aditamento de norma penal para incluir elemento que não compõe a configuração originária do tipo penal criado pelo legislador, é passo demasiadamente largo e desprovido da cautela necessária.

(Recurso em Habeas Corpus $n^{\circ}$ 9.191), também indeferido. Interpôs recurso extraordinário (RE $n^{\circ}$ 191.029), indeferido na origem e não conhecido o agravo (Al $n^{\circ} 336.299$ ), eis que intempestivo. Seguiu-se agravo regimental, igualmente denegado. Interpostos 5 embargos declaratórios, todos rejeitados. Daí, pois, a impetração do writ pleiteando o trancamento da ação penal com alegação de haver constrangimento ilegal pelo recebimento da denúncia enquanto ainda pendente de apreciação impugnação do lançamento apresentada em sede administrativa, consoante facultado pelo Decreto $\mathrm{n}^{\circ}$ $70.235 / 72$, que rege o processo administrativo fiscal. Em posição minoritária, os Ministros Joaquim Barbosa, Carlos Britto e Ellen Gracie não aderiram à sustentação. 
Nem se cogite argumentar que o tratamento da questão da forma como se apresenta seria consentâneo de uma política de arrecadação tributária, pois ao se condicionar a persecução criminal ao ato administrativo de lançamento tributário se está, ao fim e ao cabo, abrindo mão do tipo penal estabelecido pela legislação.

Deve-se lembrar que uma política de arrecadação de tributos não permite à sociedade que ganhe mais. Muito pelo contrário, o prejuízo é imenso, especialmente para aqueles que cumprem suas obrigações fiscais, pagando o preço módico por viverem em uma democracia sob à luz de regras estabelecidas.

A intervenção enérgica do Direito Penal - como última ratio - nos delitos desse jaez não detém caráter extravagante para lograr arrecadação. Antes ao contrário, vale-se como estímulo de combate a prática sonegatória.

É que nos crimes contra a ordem tributária, especialmente nos de sonegação de impostos - deve-se considerar -, a preocupação não pode ocorrer somente em função da necessidade arrecadatória do Estado, mas necessitam ser observados os interesses da coletividade, ou seja, a prioridade é a proteção de uma ordem econômica justa.

Essa proteção que se menciona, só possui chances de alcançar sucesso a partir de uma tutela estatal com força de intervenção suficiente para por termo a prática criminosa.

Tal intervenção, acredita-se, somente é capaz de advir do estabelecimento de uma proteção que apenas o Direito Criminal pode the proporcionar, de modo a propiciar que nenhum sonegador fuja à responsabilidade de divisão dos encargos tributários da sociedade.

Contudo, ao se estabelecerem leis, jurisprudências e súmula vinculante tais quais os expostos, amplia-se consideravelmente os riscos de impunidade, pois reflete o exercício de controle político na tentativa de arrecadar mais tributos em prejuízo ao jus puniendi estatal. Em última análise, exclui-se do poder judiciário a verificação da ocorrência de crime, colocando-a sob a responsabilidade da Administração Pública.

Consequentemente, a definição de que há ou não tributo - crédito tributário - acaba sendo atribuição exclusiva do Fisco, e o Poder Judiciário fica vinculado àquela decisão. Isto é, "definir se há ou não um elemento (objetivo) do crime é atribuição de um órgão de fora do Poder Judiciário". ${ }^{46}$ Admitir essa possibilidade é conferir à Administração Fiscal o poder de conceder imunidade penal.

${ }^{46}$ FISCHER, Douglas. Os paradoxos da Súmula Vinculante $n^{\circ}$ 24/STF: as contradições, a não compreensão de como se tipifica o crime material de sonegação fiscal, a impunidade e a agravação da situação do réu 
Portanto, condicionar a tipicidade do crime do artigo $1^{\circ}$ da Lei 8.137/1990 ao lançamento definitivo do tributo é, pois, desastroso, na medida em que evidentemente se está submetendo a tutela penal aos interesses arrecadatórios do Fisco, e, via de consequência, conferindo manto sagrado de impunidade aos sonegadores de impostos.

\section{CONCLUSÃO}

A ordem mundial vive um constante processo de transformação, notadamente sob o seu espectro econômico, que altera substancialmente as relações sociais. Assumem protagonismo, nesse contexto, as questões criminais, que evoluem de uma criminalidade de massa para uma criminalidade de poder, estabelecendo novos perigos.

O crime, em uma sociedade eminentemente econômica, não mais representa hipótese obsoleta em que Caio se apropria, mediante fraude ou violência física, de bem pertencente a Tício. Na verdade, a criminalidade contemporânea é representada pela delinquência econômica, que transpõe os conflitos de Direito Penal a uma sujeição passiva coletiva e social.

Sob este prisma, o viés protetivo clama pela intervenção do que se convencionou chamar de Direito Penal Econômico, apto a tutelar a forma complexa de cometimento desses novos delitos em razão da necessidade de manutenção de uma ordem econômica justa e organizada.

Nesse contexto, os estudos do sociólogo americano Edwin Sutherland, pode-se considerar, foram determinantes na alteração da proposta do que se estabelecia como ciência da criminalidade até então. Sua concepção de crime, através do desenvolvimento da teoria da associação diferencial, permitiu identificar condutas praticadas por criminosos da alta sociedade, reconhecendo a forma diferenciada de cometimento desses delitos e vinculando-os, finalmente, aos extratos superiores da sociedade.

Reconhecida a delinquência econômica, em razão da sua especialidade frente ao Direito Penal tradicional, importante considerar a proteção dos bens jurídicos protegidos pelo Direito Penal Econômico.

Deste modo, a vinculação do tema aos crimes de sonegação fiscal demonstrou a existência de bem jurídico relacionado ao dever geral dos cidadãos de pagar impostos,

em determinados casos. In: BASTOS, Marcelo Lessa; AMORIM. Pierre Souto Maior Coutinho de. Tributo a Afrânio Silva Jardim: escritos e estudos. Rio de Janeiro: Lumen Juris, 2011. p 55-94. 
admitindo-se como equivocada a política patrimonialista que transita em torno dos temas que regulam a matéria.

Com efeito, a referência ocorre a partir do artigo 83 da Lei 9.430/1996, que impede que a Administração faça representação fiscal para fins penais antes de encerrada a instância administrativa. Trata-se da necessidade de decisão administrativa tributária final como condição de possibilidade para a incidência de norma que relata os crimes contra a ordem tributária.

Por isso a conclusão que se observa decorre da impunidade que se origina dessa posição patrimonialista que se verifica na legislação e na jurisprudência. Nó górdio de todo o apresentado, portanto, é que a tutela penal não deve se submeter aos interesses arrecadatórios da Administração sob pena de se conferir manto sagrado de impunidade aos delinquentes econômicos que sonegam impostos.

\section{REFERÊNCIAS}

BAJO FERNÁNDEZ, Miguel; BACIGALUPO, Silvina. Derecho Penal Económico. Madrid: Centro de Estudios Ramón Areces, S.A., 2001.

BRASIL. Constituição Federal. Brasília: Senado Federal, 1988. Disponível em:

<http://www.planalto.gov.br/ccivil_03/Constituicao/Constituiçao.htm>. Acesso em: 27 nov. 2012.

. Lei $n^{\circ} 8.137$, de 27 de dezembro de 1990. Define os crimes contra a ordem tributária, econômica e contra as relações de consumo, e dá outras providências. In: Diário Oficial da República Federativa do Brasil, Brasília, DF, 28 dez. 1990. Disponível em: <http://www.planalto.gov.br/ ccivil_03/leis/L8137.htm>. Acesso em: 27 ago. 2012.

. Lei ${ }^{\circ}$ 9.430, de 27 de dezembro de 1996. Dispõe sobre a legislação tributária federal, as contribuições para a seguridade social, o processo administrativo de consulta e dá outras providencias. In: Diário Oficial da República Federativa do Brasil. Brasília, DF, 28 dez. 1996. Disponível em: <http://www.planalto.gov.br/ccivil_03/leis/l9430.htm>. Acesso em: 17 ago. 2012.

. Supremo Tribunal Federal. Ementa. ADI 1571/UF. Ação Direta de Inconstitucionalidade. Procurador-Geral da República e Presidente da República, Congresso Nacional. Relator: Ministro Gilmar Mendes. 10 dez. 2003. Disponível em:

<http://www.stf.jus.br/portal/jurisprudencia/listarJurisprudencia.asp?s1=\%28ADI\%24.SCLA.+E+1 571.NUME.\%29+OU+\%28ADI.ACMS.+ADJ2+1571.ACMS.\%29\&base=baseAcordaos>. Acesso em: 20 ago. 2012.

.Supremo Tribunal Federal. Ementa. HC 81.611/DF. Ministério Público Federal e Luiz Alberto Chemim. Relator: Ministro Sepúlveda Pertence. 10 dez. 2003. Disponível em: 
<http://redir.stf.jus.br/paginadorpub/paginador.jsp?docTP=AC\&docID=78807>. Acesso em: 26 nov. 2012.

CALLEGARI, André Luis. Direito Penal Econômico e lavagem de dinheiro - aspectos criminológicos. Porto Alegre: Livraria do Advogado, 2003.

CASTILHO, Ela Wiecko Volkmer de. O Controle Penal nos Crimes Contra o Sistema Financeiro Nacional. Belo Horizonte: Del Rey, 1998.

CIPRIANI, Mário Luís Lírio. A aplicação da pena privativa de liberdade aos White-collar criminals. Revista Jurídica. Sapucaia do Sul, RS, v. 49, n. 289, 2001.

. Direito penal econômico e legitimação da intervenção estatal. In: D'AVILA, Fabio Roberto; SOUZA, Paulo Vinícius Sporleder de (Org.). Direito Penal Secundário: estudos sobre crimes econômicos, ambientais, informáticos e outras questões. São Paulo: Revista dos Tribunais, 2006.

COSTA, Elder Lisboa Ferreira da. Os delitos econômicos na atualidade. 0 crime de colarinho branco e a lavagem de dinheiro. In: D'AVILA, Fabio Roberto; SOUZA, Paulo Vinícius Sporleder de (Org.). Direito Penal Secundário: estudos sobre crimes econômicos, ambientais, informáticos e outras questões. São Paulo: Revista dos Tribunais, 2006.

DIAS, Jorge de Figueiredo e ANDRADE, Manuel da Costa. Problemática Geral das Infrações contra a Economia Nacional. In: Instituto de Direito Penal Econômico e Europeu (Coord.). Direito penal econômico e europeu: textos doutrinários. V. I. Coimbra: Coimbra, 1998.

FELDENS, Luciano. Tutela penal de interesses difusos e crimes do colarinho branco. Porto Alegre: Livraria do Advogado, 2002.

FISCHER, Douglas. Delinquência Econômica e Estado Social e Democrático de Direito. Porto Alegre: Verbo Jurídico, 2006.

- O custo social da criminalidade econômica. In: SOUZA, Arthur de Brito Gueiros (Org). Inovações no Direito Penal Econômico: contribuições criminológicas, político-criminais e dogmáticas. Brasília: ESMPU, 2011.

.Os paradoxos da Súmula Vinculante $n^{\circ}$ 24/STF: as contradições, a não compreensão de como se tipifica o crime material de sonegação fiscal, a impunidade e a agravação da situação do réu em determinados casos. In: BASTOS, Marcelo Lessa; AMORIM. Pierre Souto Maior Coutinho de. Tributo a Afrânio Silva Jardim: escritos e estudos. Rio de Janeiro: Lumen Juris, 2011.

JAPIASSÚ, Carlos Eduardo Adriano; PEREIRA, Daniel Queiroz. Direito Penal Econômico e Tributário: uma análise histórica e comparada. In: SOUZA, Arthur de Brito Gueiros (Org.). Inovações no Direito Penal Econômico: contribuições criminológicas, político-criminais e dogmáticas. Brasília: ESMPU, 2011.

MACHADO, Hugo de Brito. Crimes contra a ordem tributária. São Paulo: Atlas, 2008. 
PANOEIRO, José Maria de Castro. As controvérsias da Lein. 8.137/1990 (sonegação fiscal) e suas repercussões econômico-criminais. In: SOUZA, Arthur de Brito Gueiros (Org). Inovações no Direito Penal Econômico: contribuições criminológicas, político-criminais e dogmáticas. Brasília: ESMPU, 2011.

PRADO, Luiz Regis. Direito Penal Econômico. 2. ed. São Paulo: Revista dos Tribunais, 2007. . Direito Penal Econômico. 3. ed. São Paulo: Revista dos Tribunais, 2009.

RODRIGUES, Anabela Miranda. Contributo para a fundamentação de um discurso punitivo em matéria fiscal. In: Instituto de Direito Penal Económico e Europeu. (Coord.). Direito penal econômico e europeu: textos doutrinários. V. Il Coimbra: Coimbra, 1999.

RODRIGUES, Savio Guimarães. O bem jurídico-penal tributário e a legitimidade constitucional do sistema punitivo em matéria fiscal. In: SOUZA, Arthur de Brito Gueiros (Org). Inovações no Direito Penal Econômico: contribuições criminológicas, político-criminais e dogmáticas. Brasília: ESMPU, 2011.

ROSA, Manuel Cortes. Natureza jurídica das penas fiscais. In: Instituto de Direito Penal Econômico e Europeu (Coord.). Direito penal econômico e europeu: textos doutrinários. V. II. Coimbra: Coimbra, 1998.

SOUZA, Arthur de Brito Gueiros. Da criminologia à política criminal: direito penal econômico e o novo direito penal. In: SOUZA, Arthur de Brito Gueiros (Org.). Inovações no Direito Penal Econômico: contribuições criminológicas, político-criminais e dogmáticas. Brasília: ESMPU, 2011.

STRECK, Lenio Luiz. Hermenêutica Jurídica $\mathbf{e}(\mathrm{m})$ crise: uma exploração hermenêutica da construção do Direito. Porto Alegre: Livraria do Advogado, 2005.

SUTHERLAND, Edwin H. White Collar Crime. Lexington. KY, 2010.

Recebido em: 20.12.2012

Revisado em: 07.02.2013

Aprovado em: 26.03 .2013 